\title{
DIVERSITAS JENIS DAN KEMELIMPAHAN AVIFAUNA DI SUB URBAN KOTA MADIUN BAGIAN BARAT
}

\author{
Bingar Diky Linggarjati, Nurul Kusuma Dewi, Umi Nur Khasanah, Yuliana \\ Program Studi Pendidikan Biologi, FPMIPA, IKIP PGRI MADIUN \\ bingardicky@yahoo.co.id \\ Diterima 11 Mei 2014 disetujui 5 Juli 2014
}

\begin{abstract}
Sub urban of madiun region is area of the border between urban and rural development which experience a lot of road construction and the settlement. This is resulted in damage to the natural habitat of various species of birds. Damage to vegetation or habitat, caused a change in the adaptability of birds that could potentially affect the abundance of birds. The purpose of the study was to determine the type and abundance of bird in the west of sub urban Madiun. The method used is the encounter rates. Results from observational studies with a total of 75 hours indicates the total number of birds species were more abundant in the morning than the afternoon. The most abundant bird is Collocalia fuciphaga with the amounts 576 and a value of abundance 76.8, There are three species that protected by laws: Alcedo meninting, Cloris todirhamphus, and Aethopyga mystacalis. Eastern region is the highest point meeting of bird observation
\end{abstract}

Keywords : diversity, avifauna, sub urban, habitat loss

\section{PENDAHULUAN}

Tekanan terhadap kehidupan berbagai spesies dan kerusakan habitat alami akan terus berlanjut. Langkah studi ilmiah yang harus dilakukan adalah mengupayakan pengawetan, pemanfaatan, dan pelestarian keanekaragaman hayati dengan cara mengidentifikasi daerah-daerah kaya akan keanekaragaman hayati (Atmoko, 2001). Potensi tekanan terbesar terjadi di wilayah perkotaan. Menurut Rosana dalam Rusmendro et al. 2009. kota merupakan pusat berbagai aktivitas manusia dengan tingginya arus urbanisasi yang berdampak pada tingkat kebutuhan lahan.

Penggunaan lahan dapat berupa pemukiman dan pembangunan dalam skala kecil maupun besar (Missana et al., 2003). Alih fungsi lahan telah mengubah, mendegradasi dan merusak bentang alam dalam skala luas. Kerusakan habitat mendorong spesies dan bahkan seluruh komunitas menuju ambang kepunahan. Ancaman utama pada keanekaragaman hayati akibat kegiatan manusia adalah kerusakan habitat, fragmentasi habitat, degradasi habitat (termasuk polusi), perubahan iklim global, pemanfaatan spesies yang berlebihan untuk kepentingan manusia, invansi spesies-spesies asing dan meningkatnya penyebaran penyakit serta sinergi dari faktor-faktor tersebut. Spesies dan komunitas yang terancam punah menghadapi sedikitnya dua atau lebih dari masalah tersebut sehingga mendorong kepunahan dan menyulitkan usaha perlindungan (Indrawan et al., 2007).

Aktivitas perubahan fungsi lahan tersebut secara signifikan mengubah biodiversitas, kondisi tanah, aliran air dan sedimen (Missana et al., 2003). Biodiversitas merupakan komponen yang sensitif terhadap perubahan fungsi lahan (Zebish et al., 2003). Pernyataan ini ditunjukkan dengan adanya kepunahan spesies yang luar biasa akibat aktivitas manusia (Chemici et al., 2003). Burung merupakan salah satu spesies yang secara langsung mengalami penurunan populasi akibat perluasan urbanisasi (Biamonte et al, 2011). Penelitian lainnya dari komunitas burung di perkotaan melaporkan bahwa urbanisasi berdampak pada penurunan kekayaan jenis burung dan peningkatan kemelimpahan (Fardila dan Sjarmidi, 2012). Penurunan spesies burung tidak 
hanya berpengaruh pada populasinya tetapi juga akan mempengaruhi semua komposisi komponen di dunia (Ramirez, 2010)

Burung adalah avifauna yang dijumpai hampir di setiap tempat dan mempunyai posisi penting sebagai salah satu kekayaan satwa Indonesia (Hernowo, 1985 dalam Rusmendro et al., 2009). Studi ekologis menyebutkan bahwa burung mempunyai hubungan yang baik dengan lingkungan, sehingga dapat dijadikan indikator kesehatan lingkungan dan keanekaragaman hayati (Rudyanto 1999 dalam Rusmendro 2009). Peran fungsional burung dalam ekosistem adalah penyebaran biji, penyerbukan, pengendalian hama dan dekomposisi (Sekercioglu et al., 2004). Faktor yang mempengaruhi keberadaan burung di lingkungan antara lain ukuran dan struktur vegetasi, kompetisi dengan spesies, predator, serta residu pestisida (Chace et al., 2004). Vegetasi merupakan elemen struktur dasar dalam habitat terestrial (Lughadha et al., 2005). Peranan vegetasi dalam ekosistem diantaranya sebagai penyedia makanan, mengontrol erosi dan digunakan untuk tempat tinggal spesies (Balvanera et al., 2006). Indonesia termasuk lima negara dengan biodiversitas tinggi yaitu menempati urutan kelima dengan perolehan \pm 1539 jenis burung (Andrew, 1992; Atmoko, 2001).

Tingginya tingkat biodiversitas ini tidak ditunjang dengan data-data dan informasi mengenai penyebarannya, taksonominya masih terbatas dan tidak terdokumentasi dengan baik. Informasi tidak hanya menekankan pada jenis spesies tetapi lebih berprioritas pada banyaknya spesies (Atmoko, 2001). Berdasarkan hal tersebut, maka perlu diadakan eksplorasi persebaran burung di berbagai daerah, sehingga dapat terkumpul dalam database guna mendukung program biokonservasi.

Wilayah sub urban merupakan kawasan yang menarik dalam melakukan penelitian pengamatan burung. Wilayah tersebut merupakan perbatasan antara perkotaan dan pedesaan, sehingga mengindikasikan adanya perubahan daya adaptasi burung yang berpotensi dalam mempengaruhi kemelimpahan burung. Sub urban bagian barat kota Madiun merupakan lokasi pengamatan dengan lima titik pengamatan dimana masing-masing lokasi mempunyai berbagai variasi vegetasi yang berbeda yaitu bambu, tebu, glodokan, mangga, jati dan padi. Menurut Boren et al. (1999) perbedaan vegetasi di berbagai wilayah akan mempengaruhi komposisi komunitas burung. Sebagian besar wilayah ini merupakan lahan pertanian, tetapi akibat adanya urbanisasi wilayah ini menjadi sasaran program pembangunan. Menurut data dinas pertanian (BPS, 2013) luas lahan persawahan bagian barat kota Madiun berkisar 376 ha, luas ini mengalami penurunan $13,76 \%$ jika dibandingkan pada tahun 1998 (BPS, 1998) yaitu seluas 436 ha. Penurunan lahan pertanian diantaranya karena terdapat pembangunan jalan raya dan pemukiman, hal tersebut dapat berdampak dalam mengurangi vegetasi sebagai habitat berbagai spesies burung.

Studi pengamatan burung di wilayah tersebut perlu dilakukan, hal ini bertujuan untuk mengetahui diversitas jenis dan kemelimpahan burung sehingga dapat mendukung program biokonservasi yaitu mengetahui dampak kegiatan manusia terhadap alam dan mempelajari keanekaragaman hayati. Manfaat lainnya yaitu memberikan masukan pada perencana kota untuk mempertahankan habitat burung yang sesuai ditengah krisis ekosistem alami di daerah perkotaan/sub urban, akibat ekpansi urbanisasi secara besar-besaran. Penelitian ini bertujuan untuk mengetahui jenis burung dan kemelimpahannya di sub urban barat kota Madiun.

\section{METODE}

Lokasi pengamatan terletak di sepanjang sub urban bagian barat kota Madiun pada 7036'58,56"S dan $111^{03} 1^{\prime} 06,75^{\prime} \mathrm{T}$ dengan lima titik pengamatan yaitu bagian ujung selatan, sub median selatan, median, sub median timur dan ujung timur. Wilayah ujung selatan dekat dengan kebisingan dan banyak pemukiman serta keanekaragaman tumbuhan sedang dengan vegetasi dominan pohon mangga. Wilayah sub median selatan 
dekat dengan sungai, area persawahan, dan keanekaragaman tumbuhan rendah dengan vegetasi dominan pohon jati. Median merupakan wilayah pertengahan yang cukup jauh dari kebisingan dan keanekaragaman tumbuhan sedang dengan vegetasi dominan bambu dan mangga. Wilayah Sub median timur dekat dengan sungai, pemukiman, dan keanekaragaman tumbuhan rendah dengan vegetasi dominan pohon lamtoro. Wilayah ujung timur dekat dengan pertanian, sungai, pemukiman, dan keanekaragaman tumbuhan sedang dengan vegetasi dominan jati, bambu, tebu, dan mangga serta tidak terlalu bising. Lokasi pengamatan dapat dilihat pada gambar 1 .

Penelitian ini dilakukan pada tanggal 8-12 Pebruari 2014. Pengamatan dilakukan

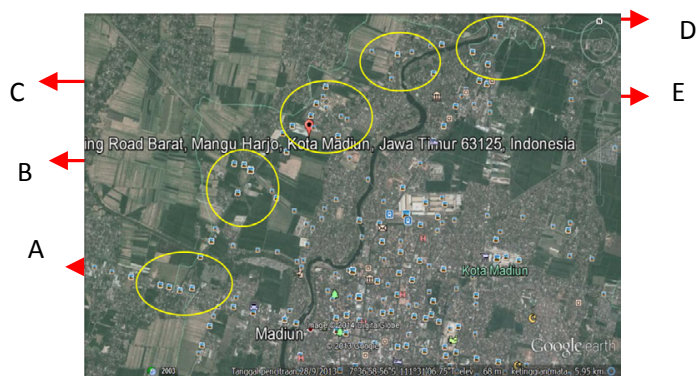

Gambar 1. Lokasi titik pengamatan, a) Ujung Selatan, b) Sub Median Selatan, c) Median, d) Sub Median Timur, e) Ujung Timur (Sumber : Google Earth)

pagi hari pada pukul (06.00 WIB-09.00 WIB) dan sore hari (15.00 WIB-18.00 WIB). Peralatan yang digunakan dalam penelitian ini adalah teropong binokuler, jam tangan, notes, kamera, dan buku panduan lapangan burung Sumatera, Jawa, Bali, dan Kalimatan oleh Mc. Kinnon et al. (2007)

Pengamatan diawali dengan penelusuran sepanjang jalur dan penentuan titik pengamatan. Langkah selanjutnya melakukan pengamatan utama dengan mendata burung di masing-masing lokasi pengamatan, meliputi pencatatan jenis burung dan menghitung jumlah spesies burung pada setiap titik pengamatan.

Data yang diperoleh dianalisis dengan menggunakan metode encounter rate untuk menentukan skala urutan kemelimpahan dengan penggunaan tingkat pertemuan, adapun penentuan skala urutan kemelimpahan menurut Bibby et al., (1998) adalah sebagai berikut:

Tabel 1. Penggunaan Tingkat Pertemuan untuk Menentukan Skala Urutan Kemelimpahan

\begin{tabular}{ccc}
$\begin{array}{c}\text { Kategori } \\
\text { kemelimpahan } \\
\text { (Jumlah } \\
\text { Individu } \\
\text { / 10 Jam } \\
\text { Pengamatan) }\end{array}$ & $\begin{array}{c}\text { Nilai } \\
\text { kemelimpahan }\end{array}$ & $\begin{array}{c}\text { Skala } \\
\text { Urutan }\end{array}$ \\
\hline$<0,1$ & & \\
$0,1-2,0$ & 1 & Jarang \\
$2,1-10,0$ & 2 & Tdk umum \\
$10,1-40,0$ & 3 & Sering \\
$<40,0$ & 4 & Umum \\
& 5 & Melimpah
\end{tabular}

\section{HASIL DAN PEMBAHASAN}

Berdasarkan hasil pengamatan yang dilakukan di lokasi berbeda, jumlah burung yang didapatkan adalah 21 spesies burung. Jenis burung pada ujung selatan berjumlah 14 spesies, sub median selatan 10 spesies, median 14 spesies, sub median timur 12 spesies, ujung timur 16 spesies. Data menunjukan pengamatan pagi lebih banyak jenisnya dibandingkan dengan pengamatan pada sore hari, yaitu 19 jenis spesies pada pagi hari dan 15 jenis spesies pada sore hari.

Perbedaan keanekaragaman tersebut diasumsikan adanya tipe burung yang bersifat diurnal yaitu beraktivitas pada pagi hari untuk mencari makan, sedangkan pada sore hari kecenderungan beberapa jenis burung beristirahat, bertengger atau berdiam diri (Rusmendro, 2009). Perbedaan keanekaragaman juga disebabkan adanya pengaruh hujan saat pengamatan. Titik pengamatan area ujung timur mempunyai jumlah jenis terbanyak yaitu 16 jenis spesies, hal ini dikarenakan lokasi tersebut tidak terlalu bising, vegetasi yang cukup, terdapat lahan perkebunan, sungai dan banyak terdapat semak-semak serta lokasi habitat cukup luas. Vegetasi dominan di sepanjang jalur pengamatan adalah tebu, padi, jati, dan bambu. Perkebunan tebu 
merupakan vegetasi yang disukai burung karena terdapat 3 spesies yang ditemui dalam pengamatan.

Keanekaragaman jenis spesies burung pada pagi dan sore hari dapat dilihat pada tabel 2.

Keanekaragaman jenis burung tersebut perlu diklasifikasikan menurut taksonomi tingkat familia, habitat dan jenis pakan, sehingga dapat mengetahui karakteristik jenis masing-masing spesies. Klasifikasi jenis burung dapat dilihat pada tabel 3 tentang burung di sub urban bagjian barat kota Madiun berdasarkan habitat dan jenis pakannya.

Tabel 2. Jenis Burung pada pengamatan pagi dan sore hari

\begin{tabular}{lcccc}
\hline \multirow{2}{*}{ No } & \multirow{2}{*}{ Titik Pengamatan } & \multicolumn{3}{c}{ Jenis burung } \\
\cline { 3 - 5 } & Pagi & Sore & Total \\
\hline 1 & Ujung Selatan & 12 & 9 & 14 \\
2 & Sub Median Selatan & 6 & 5 & 10 \\
3 & Median & 14 & 10 & 14 \\
4 & Sub Median Timur & 12 & 5 & 12 \\
5 & Ujung Timur & 14 & 8 & 16 \\
\hline & Jumlah Jenis & $\mathbf{1 9}$ & $\mathbf{1 5}$ & $\mathbf{2 1}$ \\
\hline
\end{tabular}

Tabel 3. Deskripsi beberapa jenis burung yang dominan ditemukan:

\begin{tabular}{|c|c|c|}
\hline No & Titik Pengamatan & Deskripsi \\
\hline 1 & Collocalia fuciphaga & $\begin{array}{l}\text { Berukuran agak kecil }(12 \mathrm{~cm}) \text {. Tubuh bagian atas coklat } \\
\text { kehitaman. Tunggir coklat atau keabu-abuan lebih pucat } \\
\text { (di Jawa) atau coklat tua (di Sumatera dan Kalimantan: } \\
\text { ras vestita). Ekor sedikit menggarpu, tubuh bagian } \\
\text { bawah coklat. Di lapangan, umumnya sulit dibedakan } \\
\text { dengan Walet sarang-hitam, Walet sarang-lumut, dan } \\
\text { Walet gunung, kecuali jika berada di sarang. Iris coklat } \\
\text { tua, paruh dan kaki hitam. }\end{array}$ \\
\hline 2 & Passer montanus & $\begin{array}{l}\text { Berukuran sedang }(14 \mathrm{~cm}) \text {, berwarna coklat. Mahkota } \\
\text { berwarna coklat berangan, dagu, tenggorokan, bercak } \\
\text { pipi dan setrip mata hitam, tubuh bagian bawah kuning } \\
\text { tua keabu-abuan, tubuh bagian atas berbintik-bintik } \\
\text { coklat dengan tanda hitam dan putih. Burung muda: } \\
\text { berwarna lebih pucat dengan tanda khas yang kurang } \\
\text { jelas. Iris coklat, paruh abu-abu, kaki coklat. }\end{array}$ \\
\hline 3 & Pycnonotus aurigaster & $\begin{array}{l}\text { Berukuran sedang }(20 \mathrm{~cm}) \text {, bertopi hitam dengan tunggir } \\
\text { keputih-putihan dan tungging jingga kuning. Dagu dan } \\
\text { kepala atas hitam. Kerah, tunggir, dada dan perut putih. } \\
\text { Sayap hitam, ekor coklat. Iris merah, paruh dan kaki } \\
\text { hitam. }\end{array}$ \\
\hline 4 & Lonchura leucogastroides & $\begin{array}{l}\text { Bondol agak kecil }(11 \mathrm{~cm}) \text {, berwarna hitam, coklat, } \\
\text { dan putih, bertubuh bulat. Tubuh bagian atas coklat } \\
\text { tanpa coretan, muka dan dada atas hitam; sisi perut dan } \\
\text { sisi tubuh putih, ekor bawah coklat tua. Perbedaannya } \\
\text { dengan Bondol perut-putih: tanpa coretan pucat pada } \\
\text { punggung dan sapuan kekuningan pada ekor, pinggiran } \\
\text { bersih antara dada hitam dan perut putih, sisi tubuh } \\
\text { putih (bukan coklat). Iris coklat, paruh atas gelap, paruh } \\
\text { bawah biru, kaki keabu-abuan. }\end{array}$ \\
\hline
\end{tabular}




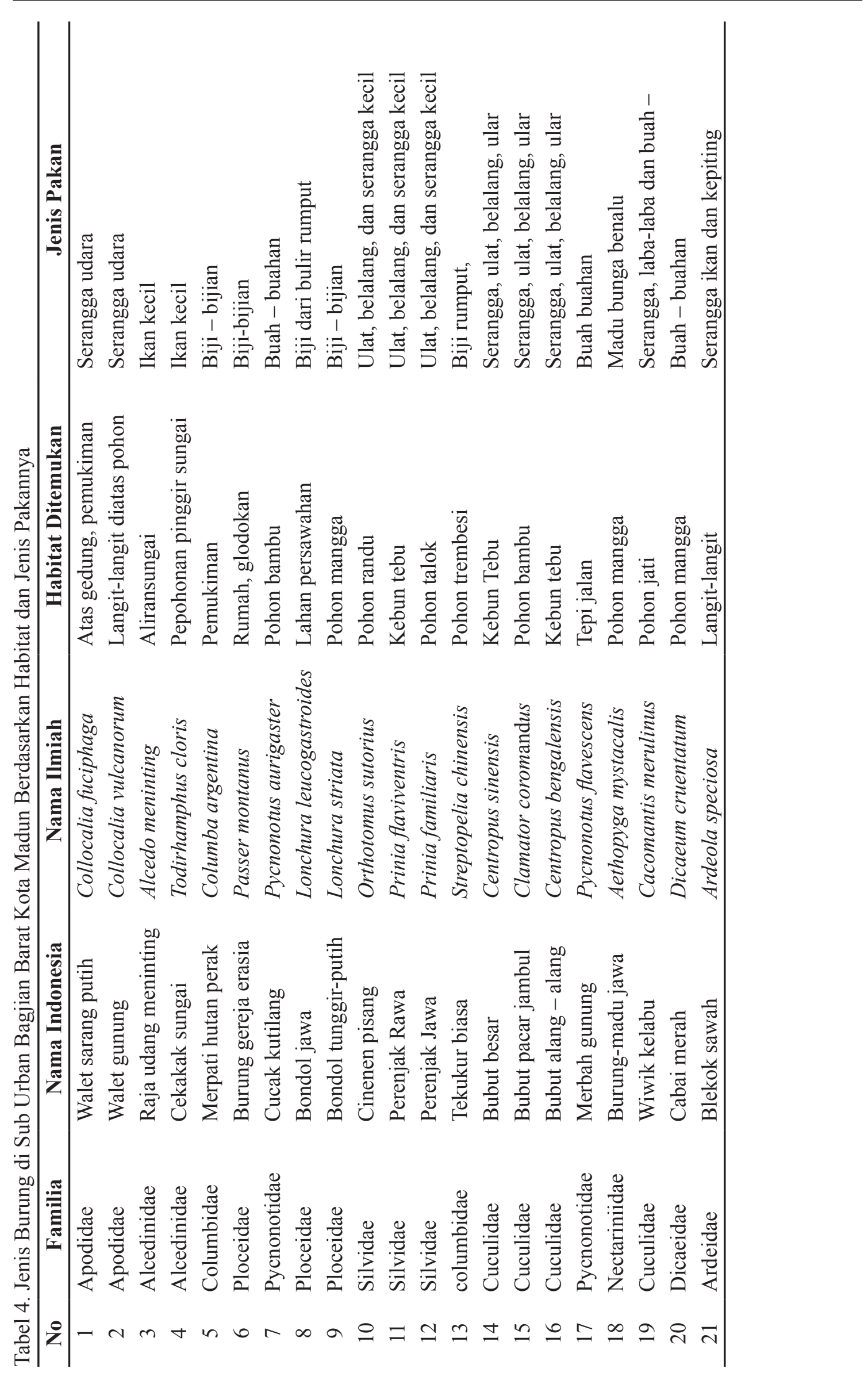


Diversitas Jenis dan Kemelimpahan Avifauna di Sub Urban Kota Madiun Bagian Barat

Tabel 5. Skala Urutan Kemelimpahan Jenis Burung

\begin{tabular}{clccc}
\hline No & \multicolumn{1}{c}{ Spesies } & $\begin{array}{c}\text { Nilai Kategori } \\
\text { Kemelimpahan }\end{array}$ & $\begin{array}{c}\text { Nilai } \\
\text { Kemelimpahan }\end{array}$ & Skala Urutan \\
\hline 1 & Collocalia fuciphaga & 76,8 & 5 & Melimpah \\
2 & Collocalia vulcanorum & 7,3 & 3 & Sering \\
3 & Alcedo meninting & 0,26 & 2 & Tidak umum \\
4 & Todirhamphus cloris & 1,73 & 2 & Tidak umum \\
5 & Columba argentina & 5,8 & 3 & Sering \\
6 & Passer montanus & 21,2 & 4 & Umum \\
7 & Pycnonotus aurigaster & 19,8 & 4 & Umum \\
8 & Lonchura leucogastroides & 31,3 & 4 & Umum \\
9 & Lonchura striata & 0,13 & 2 & Tidak umum \\
10 & Orthotomus sutorius & 1,6 & 2 & Tidak umum \\
11 & Prinia flaviventris & 1,86 & 2 & Tidak umum \\
12 & Prinia familiaris & 1,6 & 2 & Tidak umum \\
13 & Streptopelia chinensis & 0,9 & 2 & Tidak umum \\
14 & Centropus sinensis & 0,26 & 2 & Tidak umum \\
15 & Clamator coromand $u s$ & 0,13 & 2 & Tidak umum \\
16 & Centropus bengalensis & 0,13 & 2 & Tidak umum \\
17 & Pycnonotus flavescens & 0,13 & 2 & Tidak umum \\
18 & Aethopyga mystacalis & 0,2 & 2 & Tidak umum \\
19 & Cacomantis merulinus & 2,0 & 2 & Tidak umum \\
20 & Dicaeum cruentatum & 2,1 & 3 & Sering \\
21 & Ardeola speciosa & 4,0 & 3 & Sering \\
\hline & & & & \\
\hline
\end{tabular}

Total jenis burung pada titik pengamatan dapat dihitung menggunakan metode encounter rates (Bibby et al. 1998). Data yang diperoleh menunjukan jenis burung dengan kemelimpahan tertinggi adalah jenis Collocalia fuciphaga (Walet sarang putih) dan nilai kemelimpahan sebesar 76,8. Collocalia fuciphaga dapat ditemui di gua, daerah lapangan, ataupun lorong gelap (Sankaran, 2000). Jenis burung dengan skala urutan tidak umum terdapat 13 jenis burung.

Berdasakan hasil pengamatan terdapat 3 spesies yang dilindungi oleh undang-undang no 7 tahun 1999 yaitu Alcedo meninting (Raja udang meninting), Todirhamphus cloris (Cekakak sungai), Aethopyga mystacalis (Burung-madu jawa).

\section{SIMPULAN}

Pada lima titik pengamatan yang berbeda terdapat 21 jenis burung dari 13 familia. Terdapat perbedaan antara pengamatan pagi dan sore hari, pada pengamatan di pagi hari ditemukan lebih banyak individu jenis burung, hal ini dikarenakan pengamatan dilakukan pada musim penghujan. Area ujung timur mempunyai jumlah jenis burung tertinggi sekitar 16 spesies. Kemelimpahan tertinggi terdapat pada spesies Collocalia fuciphaga yaitu sebesar 576 dengan nilai kemelimpahan 76,8. Berdasarkan PP no7 tahun 1999 terdapat jenis burung yang dilindungi yaitu Alcedo meninting (Raja udang meninting), Todirhamphus cloris (Cekakak sungai), Aethopyga mystacalis (Burung-madu jawa).

\section{DAFTAR PUSTAKA}

Atmoko. 2001. Burung Sebagai Indikator Keanekaragaman Hayati. Buletin Walet, $2(2): 3-5$ 
Balvanera, P., A. B. Pfisterer, N. Buchmann, J. S. He, T. Nakashizuka, D. Raffaeeli, and B. Schmid. 2006. Quantifying the evidence for biodiversity effects on ecosystem functioning and services. Ecology Letter. 9:1146-1156

Biamonte, E., L. Sandoval, E. Chacon, and G. Barrantes. 2010. Effect of Urbanization on the Avifauna in a tropical Metropolitan Area. Landscape Ecol. 26:183-194

Boren, J.C., D.M. Engle, M. W. Palmer, R. E. Masters, T. Criner. 1999. Land Use Change Effect on Breeding Bird Community Composition. J Range Manage. 52:420-430

BPS Kota Madiun.1998. Kota Madya Madiun dalam Angka (Madiun City in Figures). Madiun : BPS Kota Madiun

BPS Kota Madiun. 2013. Kota Madiun dalam Angka (Madiun City in Figures). Madiun : BPS Kota Madiun

Bibby, C., M. Jones, and S. Marsden. 1998. Expedition Field Techniques Bird Survey. London : Royal Geographical Society

Chace, J. F., and J. J. Walsh. 2004. Urban Effect on Native Avifauna : A Review. Landscape and Urban Planning. 5:124

Chemini., and A. Rizzoli. 2003. Land Use Change and Biodiversity Conservation in the Alps. J. Mt. Ecol. $7: 1-7$

Fardila., and Sjarmidi. 2012. Bird distribution along environmental gradients In North Bandung, West Java. Research Journal of Recent Sciences.1:23-32

Indrawan, M., R.B. Primack, J. Supiatna. 2007. Biologi Konservasi. Jakarta: Yayasan Obor Indonesia

Lughadha, E., J. Baillie, W. Barthlott, N. Brummit, M.R. Cheek. 2005. Measuring the fate of plant diversity: towards a foundation for future monitoring opportunities for urgent action. Phil Trans Soc B. 360:359372

MacKinnon, J., K. Philipps, B.V. Balen. 2010. Burung - Burung di Sumatera,
Jawa, Bali dan Kalimantan (termasuk Sabah, Serawak, dan Brunei Darussalam). Bogor : LIPI Seri Panduan Lapangan

Missana, S. B., A. E. Majule, and H. V. Lyaruu. 2003. Lingkages between changes in land use, Biodiversity, and land degradation on the slopes of mount Kilimanjaro, Tanzania. Lucid. $38: 1-28$

Ramirez, J. E. 2010. The Effect of Land Use Intensity on Biodiversity of Bird and Plant in the Central Mexican Mattoral of Hidalgo Mexico. Tesis tidak diterbitkan. Mexico: Eastern New Mexico University

Rusmendro. 2009. Perbandingan Keanekaragaman Burung pada Pagi dan Sore Hari di Empat Tipe Habitat di Wilayah Pengandaran Jawa Barat. Vis Vitalis. 2:8-16

Rusmendro, H., Ruskomalasari, A. Khadafi, H. B. Prayoga, L. Apriyanti. 2009. Keberadaan Jenis Burung pada Lima Stasiun Pengamatan di Sepanjang Daerah Aliran Sungai (DAS) Ciliwung Depok Jakarta. Vis Vitalis. 2:50-64

Sankaran, R., 2000. The status and conservation of the Edible-nest Swiftlet (Collocalia fuciphaga) in the Andaman and Nicobar Islands. Biological Conservation. 97:283294

Sekercioglu, C.H., G. C. Daily, P. R. Ehrlich. 2004. Ecosystem Consequences of Bird Declines. PNAS. 101:1804218047

Zebisch,M.,F.Wechsung, andH.Kenneweg. 2003. Landscape Response Functions for Biodiversity-Assessing the Impact of Land-Use Changes at the Country Level. Landscape and Urban Planning.67:157-172 